\title{
Caminhos da Educação do Campo de Nova Santa Rita/RS
}

\section{Paths of Education in the Field of Nova Santa Rita / RS}

\author{
Andressa Luana Moreira Rodrigues (andressalunana.mr@ hotmail.com) \\ Universidade Federal do Rio Grande do Sul \\ Programa de Pós-Graduação Educação em Ciências, Porto Alegre, RS, Brasil
}

Sabrina Silveira da Rosa (ssrosa2001@ yahoo.com.br)

Universidade Federal do Rio Grande do Sul

Programa de Pós-Graduação Educação em Ciências, Porto Alegre, RS, Brasil

José Vicente Lima Robaina (jose.robaina@ufrgs.br)

Universidade Federal do Rio Grande do Sul

Programa de Pós-Graduação Educação em Ciências, Porto Alegre, RS, Brasil

Resumo: Este trabalho tem por objetivo traçar um panorama sobre os caminhos percorridos pela Educação do/no Campo da E.M.E.F Rui Barbosa, de 2013 até 2019, e investigar as atividades pedagógicas introduzidas no contexto escolar desta instituição, a partir do seu Clube de Ciências. Estudo de cunho bibliográfico e descritivo, o qual se ateve para descrição dos dados, diários de bordo de um Clube Ciências, diário de bordo da COOPERB - Cooperativa Escolar, diários de estágios da Faculdade LecampoUFRGS, registros dos eventos, cursos e palestras de âmbito municipal. Percebe-se pelos dados que o Clube de Ciências alavancou o trabalho interdisciplinar da escola e também possibilitou a implantação de projetos que auxiliam na formação integral dos educandos, como a cooperativa escolar, o galinheiro pedagógico e a reestruturação do currículo escolar.

Palavras-chave: Educação do Campo; Clube de Ciências, Cooperativismo; Galinheiro Pedagógico.

Abstract: This work aims to provide an overview of the paths taken by Education in / in Campo da Emef Rui Barbosa, from 2013 to 2019, and to investigate the pedagogical activities introduced in the school context of this institution, from its Science Club. Bibliographic and descriptive article, which was used to describe the data, logbooks of a Science Club, internship diaries of Faculdade Lecampo-Ufrgs, records of events, courses and lectures at the municipal level. It can be seen from the research that the Science Club leveraged the school's interdisciplinary work and also enabled the implementation of projects that assist in the integral training of students, such as the school cooperative, the pedagogical chicken coop and the restructuring of the school curriculum.

Keywords: Rural Education; Science Club, Cooperativism; Pedagogical Chicken. 


\section{INTRODUÇÃOO}

Vou iniciar nosso trabalho contando um pouco sobre o caminho percorrido pela educação em Nova Santa Rita, desde 2013 a Secretaria de Educação direcionou seu olhar para a educação municipal e passou a repensar, principalmente, a Educação do Campo, traçando algumas metas para atingir as melhorias desejadas. Uma destas metas foi a parceria com a Instituição de ensino UFRGS, na qual 6 professoras da rede municipal de ensino que puderam cursar a graduação em Educação do Campo Lecampo.

O curso proporcionou um novo olhar sobre os procedimentos metodológicos de ensino para nossas escolas e ainda uma mudança de comportamento que levou a transformação na forma de ensinar e de estruturar os conteúdos curriculares da EMEF Rui Barbosa, uma escola do/no campo que está dentro de um assentamento do MST, atende em torno de 70 crianças, de 04 a 10 anos, em turmas multiseriadas, em turno integral e é a escola na qual nos baseamos para esse trabalho.

Para contribuir ainda mais com a expansão do ensino em Nova Santa Rita, chegou em 2016, através da seleção para professor, na Educação do Campo da UFRGS, em Porto Alegre, o professor doutor José Vicente Robaina, que, estruturando seu trabalho na universidade, pensou em um projeto para o seu tempo destinado ao programa de extensão, sendo este o Projeto de Ensino Clubes de Ciências do Campo.

Durante o andamento das aulas de química, com o professor Robaina, foi oferecido às alunas participantes do curso a possibilidade da criação de um Clube de Ciências para as escolas das quais as graduandas pertenciam.

Uma das acadêmicas, que era e ainda é diretora da EMEF Rui Barbosa, consultou uma de suas professoras e com apenas um "SIM", aceitaram o desafio de construir um Clube de Ciências na Escola do Campo EMEF Rui Barbosa.

O primeiro conflito de ideias foi quando ao realizar o projeto perceberam que a escola não tinha um laboratório de ciências. Vieram as dúvidas: "como fazer? ”, "Como vamos iniciar?", "Por onde começar?".

Com o início das atividades, recebemos uma formação, na escola, com o coordenador do projeto, durante uma manhã de planejamento coletivo, sobre como 
Edição Especial: XVI Encontro sobre Investigação na Escola - EIE

implantar um Clube de Ciências na escola e desmistificar a visão de laboratório com vidrarias e jalecos para trabalhar ciências.

Aos poucos, percebeu-se que para a escola não seria necessário que o Clube de Ciências se tornasse algo extracurricular, mas sim, que poderia fazer parte do currículo escolar e foi tomando forma e se tornando referência para as aulas desta escola.

A primeira atividade realizada no Clube de Ciências, após a implantação do projeto, foi pensar o nome, que se oficializou "Clube de Ciências Saberes do Campo (CCSC)", e houve a criação e eleição do mascote do clube, as quais foram realizadas com as famílias e os educandos.

O mascote escolhido foi a coruja, pois representa sabedoria.

As atividades do Clube de Ciências Saberes do Campo envolvem as crianças da pré-escola ao $5^{\circ}$ ano em turno integral, todas as semanas, nas quintas-feiras, no período da manhã. Embasadas em um calendário programático feito com base nos eixos temáticos, conforme necessidades dos educandos, que se relacionam com as demais atividades da sala de aula.

No início das atividades, em 2016, a professora coordenadora era a responsável por todo o conteúdo abordado nos estudos do CCSC, no qual as demais colegas assistiam as atividades e depois aplicavam com seus educandos, adequando às necessidades de cada turma.

Em 2017, surgiu a ideia de cada semana uma das professoras orientar as atividades, ou seja, elegia-se com o grupo de educadores o eixo temático do trimestre e se fazia um calendário com as atividades programáticas para cada educadora e as mesmas realizavam as atividades adequando os conteúdos para todas as turmas e, assim, fez-se ciências no ano de 2017, na EMEF Rui Barbosa, e foi onde as professoras com suas diferentes formações (educação física, pedagogia, geografia) tiveram que pesquisar e entender os conteúdos que iriam ministrar.

No ano de 2018, com mais uma nova reformulação para apresentarem os conteúdos de ciências trabalhados no CCSC, foi pensando que cada educadora iria apresentar seu conteúdo com o auxílio dos seus educandos, ou seja, os colegas iriam apresentar e desenvolver o conteúdo trabalhado. 
Edição Especial: XVI Encontro sobre Investigação na Escola - EIE

Foi uma mudança significativa, pois, além de trabalhar com eixos temáticos, além de partir os conteúdos a serem trabalhados com os educandos conforme necessidade da sua realidade e trazendo para dentro da escola o contexto prático dessas crianças, também é trabalhado autonomia, autoestima e pesquisa por parte dos educadores e educandos.

\section{COOPERB - Cooperativa Escolar do Alunos da Escola Rui Barbosa}

A oportunidade da criação de Clubes de Ciências nos trouxe algumas conquistas, como a Cooperativa Escolar. A Cooperativa Escolar Rui Barbosa foi um dos projetos criados a partir da pesquisa Sociológica, diálogos e visitas realizadas na comunidade escolar que nos fez identificar essa potencialidade na comunidade.

A escola está dentro de um assentamento, o Assentamento Capela, e este possui uma Cooperativa a COOPAN, a qual está muito bem estruturada e transporta alimentos para vários estados brasileiros como São Paulo, Paraná e até para outros países como Uruguai e Argentina.

A ideia de criar uma cooperativa escolar teve início a partir das visitas realizadas em 2016, pelo planejamento coletivo, onde conhecemos uma cooperativa escolar no município de Ivoti e percebemos que seria muito adequado para nossa escola, pois segundo Rosa (2020) a escola busca o educar pelo entorno, trabalhando conteúdos que sejam significativos e façam sentido para os educandos, embasados pela necessidade de uma comunidade escolar e aproveitando os saberes populares dos envolvidos.

Durante o primeiro trimestre de 2018 iniciamos o Clube de Ciências Saberes do Campo com o tema Cooperativismo, pois ao retornarmos das férias de verão percebemos que as formigas haviam tomado conta da nossa horta.

A escola tem como um dos seus objetivos integrar e aproximar a comunidade escolar à escola, por isso iniciamos nosso estudo enviando aos familiares uma pergunta: “Como podemos afastar as formigas da nossa horta, sem matá-las?". Tivemos vários retornos e a partir deste momento passamos a estudar cientificamente o comportamento das formigas e toda a estrutura de um formigueiro.

Enquanto estudávamos as formigas e sua organização cooperativa também íamos pensando em como estruturar a nossa cooperativa escolar, assunto do qual nenhuma das educadoras tinha experiência para contribuir nesta construção. Novamente contamos com o apoio da comunidade para contribuir neste aprendizado. 
A partir das relações do homem com a realidade, resultantes de estar com ela e de estar nela, pelos atos de criação, recriação e decisão, vai ele dinamizando o seu mundo. Vai dominando a realidade. Vai humanizando-a. Vai acrescentando a ela algo de que ele mesmo é o fazedor (FREIRE, 1991, p. 51).

Convidamos alguns colaboradores de cooperativas próximas à escola para nos explicarem como funcionavam as cooperativas as quais eles pertenciam. E assim, unindo comunidade e escola, nos tornando "fazedor", fomos formando nossa cooperativa escolar.

A primeira necessidade da cooperativa foi a criação do nome e após algumas sugestões surgiu COOPERB (Cooperativa Escolar dos Alunos da Escola Rui Barbosa). Como segunda etapa veio a necessidade de um logo para a cooperativa, tivemos que estudar e compreender o que era uma logomarca e para que servia.

Tivemos que entender o que era necessário estar presente em uma logomarca de cooperativas, que para o nosso caso, teria que ter dois pinheiros (necessidade universal das cooperativas, todas precisam ser representadas por dois pinheiros pois significa o trabalho em união e também um pinheiro é o social e outro o capital) um círculo para simbolizar a igualdade e as formigas (caso específico da nossa cooperativa que surgiu a partir do estudo científico das formigas).

Cada turma construiu seus logos e elegeram o que mais gostaram. Na sequência reuniram-se todos os alunos para eleição de um único logo que representasse a nossa cooperativa. Sendo eleito o logo da aluna Eduarda da Rosa Marcon, na época do quarto ano.

A COOPERB teve sua criação em 21 de junho de 2018 com a eleição de uma diretoria (composta por oito membros) e seu conselho fiscal (composto por três titulares e três suplentes), agora os educandos que fazem parte da diretoria aprenderam a fazer o fluxo de caixa e a escreverem uma ata.

Mais uma conquista para a E.M.E.F Rui Barbosa, mais uma conquista para a Educação do Campo de Nova Santa Rita. Criada a cooperativa tivemos que escolher quais objetos de aprendizagem iríamos construir, precisávamos de algo que realmente nos representasse que tivesse um objetivo ecológico e social.

Se iniciou com o sabão derretido, usaram um sabão e após derretê-lo e acrescentar outros ingredientes faziam 3 barras de sabão, mas não funcionou como esperavam, ele 
derretia rapidamente e tiveram críticas construtivas de mães que adquiriram o produto e não aprovaram.

No segundo momento se fez bolacha amanteigada, mas o custo ficou alto e para baratear teriam que usar a margarina a qual foi reprovada pelos educandos, pois os mesmos sabem que a margarina só falta um ingrediente para virar plástico e de saudável ela não possui nada, esse produto foi reprovado também.

Então surgiu a ideia da diretora da escola, que gosta e faz artesanato, de comprar as sacolas retornáveis no mercado público em Porto Alegre e decorá-las com fuxicos e frases que tenham relação com a escola e a comunidade, e assim se fez.

E ainda, surgiu um outro produto, o sal temperado, o qual já havia sido estudado durante o Clube de Ciências e os educandos já sabiam que era mais saudável que o sal puro. Com o crescimento das atividades na COOPERB e divulgação pelas redes sociais do trabalho, a escola recebeu o convite, feito pela professora Tatiana Camargo, da UFRGS, para exporem os materiais na Expointer 2018, no stand da FETAG, ficamos felizes com a valorização do esforço e aceitaram.

Foi uma experiência importante para os educandos, pois, eles tiveram que trabalhar com o fluxo de caixa, dar troco, calcular o preço de dois ou mais produtos que os clientes adquiriam e também se auto organizarem para que não faltasse ninguém no espaço, para que tudo fosse registrado e que todos conseguissem explicar possíveis perguntas por parte dos visitantes.

Ao retornarem da Expointer viram que precisavam de mais conhecimento e que seria importante uma parceria com outros órgãos mais experientes, então a escola procurou a Sicredi (Cooperativa de crédito de Nova Santa Rita).

Foram bem recebidos e alguns dias depois a escola foi chamados para uma reunião, na SMEC, juntamente com uma representação de todas as escolas municipais da cidade para conhecer alguns representantes da Sicredi e todas as escolas foram convidadas a participar de um curso de formação para construção de cooperativas escolares, no ano de 2019, com o Professor Everaldo Marini, na cidade de Nova Santa Rita.

O coletivo educador da escola aceitou a proposta e alguns dias depois foram recebidos, na escola, uma comitiva da Sicredi para conhecer a COOPERB e seu 
Edição Especial: XVI Encontro sobre Investigação na Escola - EIE

funcionamento. Foi uma aproximação proveitosa, pois se conheceu alguns princípios do cooperativismo e se viu que tinham que mudar algumas ações para se considerarem efetivamente uma cooperativa.

Então em 2019, educadora coordenadora e os educandos, iniciaram um curso sobre cooperativismo que se estendeu por todo o ano com muito aprendizado e reorganização, onde em 02 de outubro deste ano fundou-se oficialmente a Cooperb, agora o que já era de fato é também de direito!

\section{GALINHEIRO PEDAGÓGICO: um espaço de conhecimento científico}

A construção do galinheiro foi pensada e sonhada durante dois anos pela diretora Camila Martins Grellt e por mim, professora e coordenadora do C.C.S.C, e incentivada pela professora Dr. Tatiana Souza de Camargo. Mas, em 2018, a diretora conversou com um pai de uma aluna e de forma simples, mas com muita dedicação e carinho fez o nosso primeiro galinheiro.

As crianças adoraram a ideia de ter um galinheiro na escola e logo se organizaram e trouxeram as galinhas. Com a chegada dessas aves na escola, o coletivo educador percebeu que o próximo tema para eixo temático da escola deveria ser "Galinhas". Foi elaborado um cronograma de atividades para as aulas do Clube de Ciências, no qual cada professora ficou responsável por elaborar uma aula do C.C.S.C de acordo com o tema de seu interesse.

A primeira experiência com as galinhas na escola foi bem expressiva e marcante de forma que envolveu os educandos nessa nova atividade da escola. Mas percebemos que precisavam ser feitas algumas melhorias para próximo ano, como um galinheiro bem fechado para as galinhas não fugirem para horta, um comedouro que pudesse ser armazenado comida para finais de semana e feriados e renda para pagar a alimentação dessas aves.

Em 2019, foi feito um projeto e enviado para o Sicredi para participar do Fundo Social, onde fomos contemplados com uma verba para a construção do novo galinheiro onde as galinhas pudessem caminhar por dentro de túneis sem estragar a nossa horta. Esse galinheiro foi construído por muitas mãos, ele tem um pouco das famílias das educadoras, dos familiares dos educandos e do Sicredi. O objetivo de ter esse galinheiro é de proporcionar aos educandos um espaço educativo de pesquisa científicas para 
construção do seu conhecimento, através do envolvimento interativo entre escola e comunidade.

Nesse contexto, alinhando aos preceitos da Educação do/no Campo, valorizando a vida dos trabalhadores camponeses e trazendo para a escola os conhecimentos adquiridos e construídos nessa comunidade, a escola realiza seu trabalho pedagógico embasado na teoria da aprendizagem significativa de Ausubel, construindo junto com as crianças, professores e comunidade novos saberes.

O conhecimento pode ser construído a partir da curiosidade dos educandos, foi o que aconteceu quando foi criado o galinheiro pedagógico, os educandos assim como as educadoras começaram a ficar "curiosos" sobre alguns fatos que até então eram comuns, coisas que acontecem todos os dias e acaba sendo normal, mas que às vezes não sabemos explicar. Exemplo das perguntas que os alunos foram fazendo ao longo das aulas: Como o ovo se forma dentro da galinha? Por que o ovo tranca na galinha? Quem veio primeiro o ovo ou a galinha? Por que as galinhas são ancestrais dos dinossauros? Por que a galinha "grita" quando coloca o ovo? Quando surgiu a primeira galinha? Entre outras perguntas.

Muitas dessas curiosidades nunca foram pensadas por parte dos familiares que criam essas aves, alguns pais se arriscaram a responder e utilizaram de um conhecimento empírico. Trazer para escola algo do cotidiano desses educandos é tornar as aprendizagens em algo significativo, dessa forma o aluno se percebe como sujeito atuante no mundo. Quando o educador desperta a curiosidade em seus educandos está fazendo mais do que educar e ensinar, está ensinando a pensar, questionar e a fazer perguntas e assim refletir sobre o que aconteceu e o vai acontecer. As aulas se tornam prazerosas e atraentes, e foge da "Educação Bancária" denominada por Paulo Freire. Os alunos são participantes ativos no processo de construção do seu próprio conhecimento (DEMO, 2007).

\section{ANÁLISE E DISCUSSÃo}

O C.C.S.C faz parte do PPP da escola, a partir dele nasceu outros projetos e lindos trabalhos como a cooperativa escolar e o galinheiro pedagógico. A partir dos relatos se percebe que é possível trabalhar de forma interdisciplinar e as aprendizagens educativas vão além dos muros da escola e que essas experiências contribuem para autonomia e emancipação dos estudantes. 
Edição Especial: XVI Encontro sobre Investigação na Escola - EIE

A escola tem como proposta uma Educação do Campo que valoriza os saberes e as vivências dessa comunidade. As aprendizagens significativas vão ao encontro da proposta de uma Escola do/no campo, pois enaltece os conhecimentos prévios dos educandos.

A escola deve ser um espaço de reflexão e construção de saberes para a compreensão de uma nova sociedade, seguindo com ideia de que "a educação como prática de liberdade" FREIRE (2014, p.98). Portando, a ideia de criar no espaço escolar um Clube de Ciências vai ao encontro de uma prática reflexiva, libertadora, investigadora e questionadora de novos conhecimentos.

Esta possibilidade ofertada, analisada, discutida e debatida pelos professores da escola, proporcionou aos educandos um novo olhar para a ciência e uma nova forma de visualizar o cotidiano e a comunidade onde sua escola está inserida.

\section{CONSIDERAÇÕES FINAIS}

As experiências aqui relatadas se destaca pela transformação no olhar pedagógico de um coletivo educador que soube aproveitar e perceber a necessidade de entender, estudar e compreender o significado de uma Educação do/no Campo.

A E.M.E.F Rui Barbosa de Nova Santa Rita, busca sistematizar suas práticas educativas através de um currículo construído a partir do território explorando seu ambiente real. Toda via essa construção de um currículo vivo que dialoga com seu território escolar tem provocado debates e muitas pesquisas para as educadoras da E.M.E.F Rui Barbosa.

As atividades do Clube de Ciências Saberes do Campo assim como da COOPERB e do Galinheiro Pedagógico, proporcionam aos nossos educandos experiências educativas e vivências que valorizam os saberes e o trabalho dessa comunidade.

Os desafios são muitos, mas são eles que movem o nosso fazer pedagógico que só funciona porque é trabalhado no coletivo, os educadores também se transformam perante a uma prática significativa e bela apesar dos desafios enfrentados na educação pública.

\section{6 . REFERÊNCIAS}


ARROYO, Miguel Gonzáles; CALDART, Roseli Salete e MOLINA, Mônica Castagna. Por uma Educação do Campo. 5º ed. Petrópolis, RJ: Vozes, 2011.

AUSUBEL, David. Paul; NOVAK, Joseph. Donald.; HANESIAN, Helen. Psicologia Educacional. Rio de Janeiro: Interamericana, 1980. BEHRENS, M. A.

BLASZKO, Caroline Elizabel; UJIIE, Nájela Tavares; CARLETTO, Márcia Regina. Ensino de ciências na primeira infância: aspectos a considerar e elementos para a ação pedagógica. In: UJIIE, Nájela Tavares; PIETROBON, Sandra Regina Gardacho. Educação, infância e formação: vicissitudes e que fazeres. Curitiba: CRV, 2014, p. 151-168.

DELIZOICOV, Demétrio. Ensino de Ciências: fundamentos e métodos. 2. ed. São Paulo: Cortez, 2007.

FREIRE, Paulo. Convite à leitura de Paulo Freire. São Paulo: Scipione (Série Pensamento e Ação no Magistério), 1991.

FREIRE, Paulo. Pedagogia da Autonomia: saberes necessários à prática educativa. 46 ${ }^{\mathrm{a}}$ ed. Rio de Janeiro: Paz e Terra, 2013.

MOREIRA, Marco Antônio; SOUSA, Célia Maria Soares Gomes de. "Organizadores prévios como recursos instrumentais." Melhorias do Ensino, $\mathrm{n}^{\circ}$ 7. Porto Alegre, PADES/UFRGS, 1980.

ROSA, Sabrina Silveira da; ROBAINA, José Vicente Lima. O Ensino de Ciências nas Escolas do Campo a partir da análise da produção acadêmica. Revista Insignare Scientia - RIS, v. 3, n. 2, p. 156-175, 24 ago. 2020. Disponível em: https://periodicos.uffs.edu.br/index.php/RIS/article/view/11161/7467. Acesso em: 24 nov. 2020. 